ISSN 0001-6002/2001/43/3/104-113

Acta Médica Costarricense,(C2001

Colegio de Médicos y Cirujanos

\title{
Evolución de la medicina: Pasado, presente y futuro
}

Juan Jaramillo-Antillón ${ }^{1}$

Importancia de la Medicina en la Sociedad: Hace 2.500 años, Protágoras, el más grande "sofista" griego afirmaba que "el hombre era la medida de todas las cosas". Desde esos tiempos y bajo las enseñanzas de Sócrates y Aristóteles, se fue poniendo en evidencia que el ser humano era la figura central de la historia. Y es qué, si no existiera el ser humano, no habría realizaciones, pensamiento ni espíritu. Él es el único ser con pasado conocido que vive su presente y planea su futuro. Ya qué es el que crea la historia y es el fin de la misma. Por esa razón los médicos debemos entender que no puede haber nada más noble que proteger su salud o atender su enfermedad. Si aceptamos lo anterior, se nos abre una amplia perspectiva sobre la importancia de la salud pública y la medicina en la vida de los pueblos.

Por otro lado, sí queremos tener conciencia de lo que la medicina ha significado para la sociedad, debemos recordar lo que el famoso salubrista e historiador Henry Sigerist decía al respecto" la medicina es el estudio y la aplicación de la biología en una estructura de la humanidad que es al mismo tiempo, histórica, social, económica y cultural.

El Origen Mitológico de la Medicina: En la mitología griega se dice que el Dios de la medicina era Apolo, también llamado Alexikako (el que evita los males). Era el médico de los dioses olímpicos cuyas heridas sanaba empleando una raíz de peonia.

Apolo le trasmitió el conocimiento de la medicina al centauro Quirón (hijo de Saturno), éste era el encargado de educar a los héroes griegos, Jasón, Hércules, Aquiles y muchos otros, entre los cuales se encontraba Asclepio, conocido posteriormente con el nombre latinizado de Esculapio. Por esos remotos tiempos, en Egipto 2.700 años a.C, Imhotep, arquitecto y médico de la corte del faraón Zoser, era considerado el primer médico del mundo y por ello fue divinizado por este pueblo. Asclepio

Recibido: 24 de abril de 2001.

Aceptado: 24 de julio de 2001.

${ }^{1}$ Miembro de Número, Academia Nacional de Medicina.

Correspondencia: Juan Jaramillo Antillón. Apartado 1292-1000 San José, Costa Rica. era hijo de Apolo quién lo había tenido con una joven llamada Coronis, ésta para ocultar su embarazo y deshonra provocada por ese dios, dio a luz al niño en una montaña, dejándolo ahí, donde fue criado y defendido por una cabra y cuidado por un perro. Desde niño hacía curas milagrosas y por ello los campesinos del lugar lo adoraban, llegó ya adulto a curar en forma tan magistral que incluso las "sombras" que vivían en el Hades fueron sanadas por este primer médico. Zeus enojado por haber Asclepio sanado sin su permiso a las sombras decidió destruirlo con un rayo. Desde entonces, a Esculapio se le representa sentado sosteniendo una vara a cuyo alrededor está enrollada una serpiente.

Entre los hijos de Esculapio estaban Hygieia y Panacea, que se dice asistían a los ritos del templo donde sanaban a los enfermos y alimentaban a las serpientes sagradas. Para los griegos, este animal ayudaba a curar a los enfermos, a diferencia de la tradición judía y cristiana, que por influencia del relato bíblico la consideraban representante del demonio.

El culto de Hygieia como diosa de la salud fue introducido en Roma por un grupo conocido como Epidauros (médicos griegos provenientes de esa ciudad) que llegaron a Roma en el año 239 a.C. Es representada como una joven bella y fuerte, sosteniendo en sus manos una copa (símbolo de la vida) y una serpiente arrollada en su brazo izquierdo que se dirige hacia la copa. La palabra "hygiene" se deriva del nombre de esta diosa y se refiere al cuidado de la salud tanto física como mental por parte de los médicos. Panacea es considerada la diosa griega de los medicamentos para devolver la salud y simboliza el ideal de una medicación inocua y efectiva. Desde entonces, salud y medicina o medicina y salud están estrechamente relacionadas.

Los Albores de la Medicina: Al principio de la civilización, 4000 años a.C. la medicina Mesopotámica estaba basada en la magia contra los espíritus malignos de los que el hombre tenía que ser protegido mediante conjuros para exorcizar al demonio y sacarlo fuera del cuerpo. Por esos tiempos se consideraba el mundo lleno de malos espíritus que atacaban a los mortales. Las enfermedades eran por tanto debidas a un demonio que había penetrado en el cuerpo del paciente y la forma más fácil de curarla era obligar al demonio a marcharse. Para eso eran los conjuros de los magos y en los papiros hay descripciones muy detalladas de estos. Incluso hoy, 6 mil 
años después, grupos religiosos incluyendo católicos practican aún estos superticiosos conjuros.

Por esa misma época la Medicina Egipcia era ante todo mágico religiosa y los que trataban a los enfermos eran sacerdotes entre los que estaban adivinos, que interpretaban los augurios y predecían el curso de las enfermedades. Posteriormente los egipcios superaron la magia y aparecieron los médicos sacerdotes, quienes comenzaron a dar medicamentos como el yodo para tratar los bocios, laxantes, eméticos y a hacer operaciones. Las primeras trepanaciones de cráneo con evidencias de que algunos pacientes sobrevivieron fueron realizadas por ellos.

Hipócrates: El inicio de la medicina científica se centra en la aparición en Grecia de una figura histórica excepcional símbolo del médico ideal, Hipócrates. Él creo un método de aprendizaje en medicina consistente en apoyarse en la experiencia, observando cuidadosamente al paciente, interrogándolo, conociendo sus costumbres y la forma como éstas habían repercutido en su salud y explorándolo cuidadosamente. Fue el primero en analizar los errores como la mejor forma de aprender y adquirir experiencia en el diagnóstico de las enfermedades. Mostró que algunas enfermedades se asocian a condiciones climáticas y de ambiente, como eran las fiebres maláricas. Describió además las epidemias de gripe o influenza, el cuadro clínico de la tisis (tuberculosis), la disentería, la septicemia, la epilepsia y algunos cánceres como el de la mama, útero, estómago e hígado.

Él sostenía que no puede haber nada más noble y más importante que proteger la salud o atender la enfermedad del ser humano, ya que éste es la figura central de la historia y el fin de la misma. La medicina moderna con toda su tecnología nos ha mostrado lo acertado que estaba Hipócrates con sus afirmaciones. En muchos sentidos la conservación de la salud fue en realidad la base de su medicina, él analizaba con cuidado los problemas de la higiene individual y del ambiente y la forma como influían en la salud de la población. Gracias a él, aunque solo siglos después, se ha aceptado plenamente su concepto de que el médico no solo debe curar, sino también aprender a evitar que las personas se enfermen. Los estudios del genoma humano han mostrado que no existen dos personas iguales, por eso cada uno de nosotros reacciona en forma diferente ante la enfermedad. Éste sabio médico insistía en que no existen enfermedades sino enfermos, algo que ahora aceptamos como una realidad. Hipócrates nos mostró que había que evitar la magia y las especulaciones religiosas y que el razonamiento era la base para lograr curar a los enfermos.

La importancia de la aparición de este médico radica en que separó la practica de la medicina de la magia e incluso de las especulaciones de la filosofía. Por eso ha sido considerado el padre de la medicina. En el tratamiento de los enfermos él creía en la importancia de ayudar a la naturaleza para que el organismo se recuperara. En su libro sobre la enfermedad sagrada conocida luego de él como epilepsia, él ridiculiza el supuesto origen divino de ella y la idea de que las enfermedades son causadas por dioses o demonios, algo que algunas religiones sostienen en la actualidad. Opinaba que la causa de la epilepsia se originaba en el cerebro, y no se equivocó con su diagnóstico hace 2.400 años.

El decía "el hombre debe saber que solo del cerebro proceden la alegría y las penas. Y es gracias a él que adquirimos conocimientos y sabiduría, vemos, oímos, y conocemos lo que es malo y bueno. Por el mismo órgano nos volvemos locos y de él proceden los sueños". Hipócrates no fue el autor del Juramento hipocrático, aunque lo inspiró, y tampoco el autor de la mayoría de los 70 libros del llamado "corpus hipocraticum" escrito por alumnos de su escuela de Cos.

En el año 300 a.C en la escuela médica de Alejandría, surgió el fundador de la anatomía, el griego "Herófilo". Este médico fue el primero en hacer disecciones de cadáveres en público. Reconoció el cerebro como sede de la inteligencia al igual que lo había señalado Hipócrates y en contra del criterio de Aristóteles que lo ponía en el corazón. Asoció a los nervios la sensibilidad y los movimientos y diferenció las arterias de las venas. En esa misma escuela y por el mismo tiempo "Erasistrato" se convirtió en el primer anatomista-fisiologo. Señalaba que el aire entraba por los pulmones y de ahí pasaba al corazón, en el cual se transformaba en un "pneuma" espíritu vital y de ahí era conducido por las arterias a todo el cuerpo incluyendo el cerebro. Relató que las circunvoluciones cerebrales eran más complejas en el hombre que en los animales y asoció esto a la mayor inteligencia humana. Describió los ventrículos y las meninges y el cerebelo.

No quisiera dejar pasar la oportunidad sin señalar el hecho de que, por el año 300.a.C. el historiador Tucidides en su descripción de la plaga de Atenas, señalaba por primera vez, el contagio de una enfermedad de persona a persona y describía que la infección era tan contagiosa que ni los médicos se salvaban de ella.

A partir del año 150. d.C. surgió la figura del griego Galeno de la ciudad de Pergamo, quién seguía la escuela hipocrática y sus enseñanzas predominaron por siglos. Al parecer había hecho algunas pocas disecciones de cadáveres y conocía bien los huesos y los músculos y era el mejor fisiólogo de su época. Lamentablemente debido a su mal genio y egolatría no tuvo alumnos y no fundó ninguna escuela. Posteriormente, el desarrollo del conocimiento médico entró en decadencia desde el año 300 d.C al 1300 debido a que la iglesia eliminó la lectura pagana de los textos griegos y la enseñanza de la medicina solamente se llegó a realizar en los monasterios. La medicina monástica pensaba únicamente en la curación del paciente con ayuda de Dios y por eso decayeron los saberes teóricos y se detuvo el conocimiento de la anatomía y fisiología. La disección de cadáveres fue prohibida por siglos.

Los Romanos contribuyeron a la medicina con la construcción de grandes hospitales, al principio militares y luego municipales. Inventaron un sistema de cloacas subterráneas 
para eliminar las materias fecales y distribuyeron el agua potable mediante los acueductos que abastecían a Roma con millones de galones diarios. Crearon el puesto de médico de pueblo para atender a los pobres con salarios pagados por la municipalidad. Los ricos tenían ya para esa época un médico familiar.

Los Arabes comenzaron a estudiar las fuentes médicas griegas y fue así como el persa "Avicena" por el año 1000 d.C. escribió una enciclopedia del saber médico llamada "El canon", que se utilizó por siglos como libro de texto. El famoso médico y cirujano "Albucasis" de la ciudad de Córdoba realizó con éxito la primera extirpación de un bocio. Creó una serie de toscos instrumentos quirúrgicos y un manual de cirugía donde se señalaba el empleo del cauterio para tratar las heridas. Para el año 1530, el médico italiano Girolamo Fracastoro mostró que la sífilis (morbos gallicus) era una enfermedad trasmitida por contacto sexual. Dando así lugar a la primera teoría correcta del contagio de una enfermedad de este tipo.

En ese mismo siglo, "Andres Vesalio" profesor de anatomía de la Universidad de Padua, Italia, disecaba cadáveres en público rodeado de estudiantes de medicina y enseñaba nuevamente como estaba formado el cuerpo humano. Escribió un libro monumental de anatomía "La fabrica del cuerpo humano", con bellos y exactos dibujos anatómicos. Esta obra se convirtió en la fuente de enseñanza de la anatomía no solo para los estudiantes y médicos sino también para los cirujanos.

Surgió en Francia "Ambrosio Paré" cirujano militar que llegó a ser el mejor de su época. Por "serendipia" eliminó el cauterio y los aceites hirviendo, debido a que una batalla le impidió contar con cauterio y aceites para tratar las heridas, se dio cuenta entonces que éstas evolucionaban mejor sin emplear lo anterior y se infectaban menos. En razón de eso practicó a efectuar ligadura de los vasos sangrantes con seda, creo técnicas para las fracturas y diseñó miembros artificiales para los amputados.

En el año de 1775, el doctor sir Percival Pott señaló la asociación que existía entre el cáncer del escroto y la presencia del polvo del carbón en la ropa y la piel de esa región en los deshollinadores de Londres. Él llegó a la conclusión de que el tumor era provocado por la permanencia del polvo de carbón entre los pliegues de ese escroto. Fue así como por primera vez se reconoció nada menos que la asociación causa-efecto de una sustancia química para producir un cáncer.

En 1775 , las epidemias de viruela afectaban periódicamente a Europa causando gran mortalidad. Un médico rural "Eduardo Jenner" se dio cuenta de que quiénes ordeñaban a las vacas cuyas ubres tenían lesiones de viruela no llegaban a sufrir dicha enfermedad si presentaban cicatrices de pústulas en sus manos. Con esta observación, Jenner inició la investigación médica clínica. Inoculó linfa extraída de una lesión de una ordeñadora a un joven debajo de su piel y éste desarrollo una típica pústula de viruela, luego volvió a inyectarle linfa en otro lugar y no apareció lesión ninguna. El joven se había vuelto inmune y Jenner creó así el conocimiento de la inmunidad y las vacunas.

En el campo de la salud pública y la medicina preventiva destaca "Johan Peter Frank", médico alemán, quién en 1779 publicó nueve volúmenes que tituló: Sistema Completo de Policía Médica. En ellos señalaba que las enfermedades eran causadas no sólo por factores físicos, sino que existían igual o mayor influencia nociva proveniente del medio social tales como la pobreza, la insalubridad y la mala alimentación. En el I tomo, trataba de embarazo, el parto y las enfermedades hereditarias. En el II, estudia la higiene del niño, y las enfermedades venéreas. En el III, el papel de la alimentación, el vestido y la casa en la salud. El IV y V, versaban sobre accidentes y el VI es sobre educación médica. Posteriormente, en Inglaterra en el año 1843 brilló sir Edwin Chadwick, un periodista y abogado que no tenía título de médico. Éste se interesó por los problemas sanitarios y consideraba que la suciedad producía enfermedades (algo que hoy nos parece lógico, pero que en su época era un concepto revolucionario) y sugería: recoger la basura que llenaba las calles y lotes vacíos, evacuar las aguas negras mediante desagües que condujeran a un alcantarillado adecuado y dotar de agua potable a ciudades y casas. Gracias a Chadwick la higiene británica superó a otros países y por él se creo la primera ley de sanidad con inspectores que velaban por la limpieza de Londres. Con las anteriores medidas, la infecciones disminuyeron en forma importante.

Cuando apareció la epidemia de cólera en Inglaterra en 1848 y que ocasionó la muerte a 54 mil personas, fue el "Dr. John Snow", el primer especialista en anestesia de ese país, quién conociendo las experiencias previas dedujo que la causa era el agua contaminada que se usaba para beber de ciertos pozos y habiéndose localizado estos se pudo eliminar la epidemia. Fue así como se logró demostrar que una epidemia infecciosa podía controlarse si se encontraba la causa que la generaba o por lo menos como en este caso la fuente de donde procedía.

El mejor ejemplo de una fuente de contagio creada por los médicos como una mala práctica de su profesión la señaló el médico ginecólogo "Phillipp Semmelwis", el cual trabajaba en el año 1840 en Viena en el Hospital General. Ahí, las embarazadas que daban a luz morían en una proporción que fluctuaba entre el 10 al 30 por ciento debido a la llamada "fiebre puerperal". El se dio cuenta que estas mujeres eran contaminadas por los estudiantes de medicina y los médicos ya que las exploraban sin haberse limpiado las manos incluso viniendo de autopsias. Como no le creyeron, se dedicó junto con las parteras de otro salón de partos a explorarlas $\mathrm{y}$ atender los partos previa limpieza de las manos. Con ello descendió la mortalidad al uno por ciento. Sin embargo, los médicos del hospital no le creyeron, se burlaron de el y por años no le hicieron caso. Desilucionado Semmelwis se retiró y enloqueció. Cuando el cirujano inglés "Joseph Lister" creó 
la asepsia en cirugía para disminuir las infecciones lavandose las manos en forma adecuada inicialmente con sustancias químicas y esterilizando los instrumentos con ácido fénico y posteriormente, también por serendipia, empleando agua hervida y jabón (debido a que algunos cirujanos alérgicos al fenol lo hacían con agua hervida), obteniendo los mismos resultados, el mundo médico vió como había despreciado por años las experiencias de Semmelwis con grandes pérdidas de vidas. Se observa entonces, que la arrogancia de no reconocer la necesidad de corregir errores no es un buen compañero, pero lamentablemente ha estado presente a través de la historia de la medicina. Poco a poco en las escuelas de medicina se volvió a la tesis de que las enfermedades estaban originadas por diferentes causas naturales y no por castigo de Dios. Apareció así el determinismo científico en medicina (la causalidad) y se comenzaron a estudiar con mayor intensidad los origenes de las enfermedades y el modo como evitarlas.

En 1837, el médico italiano Agostino Bassi, describió que un hongo producía la enfermedad del gusano de seda, conocida como "calcinacio o muscardine "y aunque la enfermedad era en un animal, se demostraba que en éstos existían microorganismos que las provocaban y que debía ser igual en las personas. Pocos años después, Pasteur lo confirmó en forma magistral mediante experimentos; sin embargo, como era habitual en él no le dio crédito a Bassi. Éste publicó además un artículo en 1844 señalando que el sarampión, la peste bubónica, la sífilis y el cólera eran causadas por un parásito vivo animal o vegetal que pasaba de un individuo a otros contaminándolos. Por esa época no se conocían las bacterias y por ello esta comunicación atrajo poca atención.

Los Gérmenes como Causa de Enfermedades: El siguiente paso fue la aparición en el año de 1870 de la llamada "teoría de los gérmenes como causa de las enfermedades" del químico francés Louis Pasteur. El llegó a la conclusión de que la fermentación que deterioraba los vinos y la cerveza se debía a "gérmenes vivos que llamó fermentos y que, calentando el vino se evitaba eso. A este método se le llamó posteriormente "pasteurización" y fue aplicada a la leche para evitar su contaminación y salvó muchas vidas entre los niños pequeños. Sus estudios lo llevaron a afirmar en contra de la teoría de la generación espontánea de gérmenes, prevalente hasta esa época, que estos eran los que provocaban las diferentes enfermedades y que los mismos nacen de otros preexistente y no se ven en medios estériles. Descubrió el estafilococo de los abscesos de la piel e insistió que los microbios pululan en el aire y contaminan a las personas. Esto fue confirmado por ese mismo tiempo por el médico alemán Robert Koch, al afirmar que la tuberculosis pulmonar era provocada por una bacteria que él logró cultivar de los pulmones de los enfermos con este mal. Entre ambos diagnosticaron el bacilo del carbunco, enfermedad que afecta al ganado vacuno. Y para 1882 Pasteur decía que "la rabia" era una enfermedad transmitida por la mordedura de los perros enfermos a las personas y otros animales, por una organismo tan pequeño que no se podía ver al microscopio (y que posteriormente se comprobó era un virus filtrable). El trabajo científico de Pasteur de enorme valor científico y social, sirvió para establecer posteriormente un método general de preparación de vacunas por medio de gérmenes de virulencia experimentalmente atenuada.

A pesar de que para esta época se había demostrado que los cuidados de la salud y las medidas preventivas eran muy importantes para evitar enfermedades. Por muchos siglos, el tratamiento de la enfermedad continuó siendo considerado el objetivo fundamental de la medicina. Con resultados muchas veces erróneos ya que no se contaban en muchos casos con los medicamentos modernos.

Lo anterior nos deja ver que en cuanto a conceptos, la medicina de esa época había retrocedido en algunos aspectos desde los tiempos de Hipócrates, ya que la medicina de su tiempo producto de las enseñanzas de este extraordinario hombre, nunca fue exclusivamente curativa. Por entonces sabían tratar las heridas, reducían fracturas, trepanaban el cráneo, drenaban ascitis del abdomen y pus del tórax y empleaban medicinas como extractos de corteza de sauce (acacetil-salicilico) para la fiebre y el dolor, o polvo de coral (carbonato de calcio) como antiácido y dispéptico, y extractos de la planta digitalis como tónico. Y además daban laxantes y eméticos y tenían pomadas diversas. La conservación de la salud fue, en realidad, la base de su medicina y sus alumnos dedicaban la mayor parte de su tiempo a analizar los problemas de la higiene individual y del ambiente que influían en la salud de la población. Como la población griega obedecía esas indicaciones, su esperanza de vida llegó a ser mayor de 60 años, muy por encima del promedio de 40 años de esa época en el resto del mundo y a pesar de las muertes por las guerras en que constantemente participaban los griegos y que constituían, posiblemente, la primera causa de mortalidad.

Poco a poco, con el tiempo, fue ganando aceptación el concepto de que el médico no sólo debe curar sino también evitar que las personas se enfermen y que es obligación de las escuelas de medicina desarrollar buenos programas de educación para la salud aparte de enseñar a diagnosticar y tratar la enfermedad. Por eso es importante poner al joven estudiante en contacto no sólo con hospitales y consultas médicas, sino con la población y su medio y con el entorno familiar sitio donde se gesta en muchos casos la enfermedad. Además, el estudiante debe entender que los pacientes deben ser vistos no solo como enfermos sino también como seres humanos en una dualidad inseparable. El código genético nos ha mostrado que no existen dos personas iguales, por eso, cada uno de nosotros reacciona diferente ante la enfermedad. Toma entonces nuevamente vigencia la máxima hipocrática que señala que "no existen enfermedades sino enfermos".

A través del tiempo y gracias a los conocimientos adquiridos se llevaron a la práctica, por las autoridades de salud en diferentes países, una serie de modelos llamados también paradigmas para cuidar la salud, gracias a los cuales poco a poco hemos venido mejorando los servicios de prevención y atención de la enfermedad en todo el mundo. Esos paradigmas se muestran en las siguientes páginas y se explican por sí solos. Los paradigmas nos enseñan que la salud no se le 
puede imponer a una persona o a una población. El médico, los salubristas, las enfermeras, las instituciones de salud y los gobiernos pueden ofrecer servicios para proteger la salud o para recuperarla o rehabilitarla, pero es cada persona la que ha de decidir, con base en la educación recibida, si acepta los consejos, el apoyo y las medidas de prevención y tratamiento que se le ofrecen y mantiene una estado de buena salud eliminando los malos hábitos y evitando los factores de riesgo. Además nos hacen ver que la salud depende de muchos factores y por esa razón la medicina no solo debe ser integral, en cuanto a la atención del paciente (educativa-preventiva-curativa y de rehabilitación) sino también Holística, en el sentido de la necesidad de analizar los factores condicionantes de la salud ya señalados y por eso, poco a poco como pasa en los países desarrollados debemos integrar a lo anterior la investigación biomédica básica y clínica en este proceso. De esta forma, hemos dejado de ver la salud como un simple fenómeno biológico y aceptamos la íntima relación de esta con los estilos de vida y el medio donde viven las personas.

Ahora, en la enseñanza de la medicina debemos emplear dos tipos de filosofía/ educativa por decirlo así: Una, que busca tratar las enfermedades con énfasis en el conocimiento de la patología su diagnóstico y su tratamiento. Y otra, que investiga las causas que las generan para recomendar cómo evitarlas. En realidad ambas son inseparables. Por lo tanto, debe darse para el año 2000 un lugar amplio y adecuado a la educación para la salud y la prevención de enfermedades así como al diagnóstico temprano de ellas, como estrategias claves, capaces de revolucionar la medicina moderna, haciéndola accesible a todos y dando lugar si es posible a una medicina más simple, menos costosa y sobre todo más humana. Sin descuidar la atención de la enfermedad que es también prioritaria.

Para eso hay que entender que la protección de la salud es algo complejo y no consiste únicamente en tener buenos médicos, hospitales o incluso buenas campañas preventivas. Para lograr la salud se requiere de una serie de condiciones que trascienden en mucho el campo médico e incluso el de la salud pública.

Se debe entonces crear conciencia publica de la responsabilidad compartida que tenemos las personas, las familias, la comunidad y el gobierno de cuidar la salud a lo largo de toda la vida. Por eso, siempre hemos sostenido la tesis de que este proceso debe iniciarse en el hogar donde los padres deben ser los primeros promotores de salud, para lo cual deben ser concienciados y educados. Unicamente si la población tiene un grado aceptable de salud e ingresos económicos mínimos, habrá garantía de que todos los individuos podrán disfrutar en forma adecuada de los restantes beneficios que produce el desarrollo económico como son: el trabajo, la educación, la alimentación, la vivienda el arte los deportes e incluso el amor.

Debido a las medidas tomadas en salud, estamos ahora y desde hace varios años ante una paradoja. Habiéndose mejorado la salud de la población por diferentes causas y medidas se logró una muy alta esperanza de vida y el envejecimiento de la población. Pero debido a eso, la seguridad social del país o las familias, tienen que pagar un alto costo en sus servicios médico-hospitalarios para los ancianos, en razón de que por su edad sufren de: cardiopatías, cáncer, diabetes, hipertensión, trastornos psíquicos seniles, problemas oculares, auditivos, urológicos y pulmonares entre otros. En los Estados Unidos las seis causas líderes de muerte de las personas son: las enfermedades coronarias y los accidentes cerebrovasculares, el cáncer, donde destacan el de pulmón y colon, la diabetes y sus complicaciones y la enfermedad obstructiva crónica y los accidentes.

Los factores de riesgo más serios son: el fumado, la obesidad, hipertensión, el colesterol elevado en sangre, el abuso del licor y la velocidad y la falta de ejercicios. Se considera que el fumado da lugar a la muerte prematura anualmente de 400 mil personas en ese país.

A eso hay que agregar los problemas que aumentan día a día en los pueblos, de la llamada patología social ocasionada por: el abuso del licor, el tabaco y las drogas, los embarazos de niños no deseados, y los abortos secundarios. El aumento de madres solteras, con la aparición de hogares inestables y niños agredidos, abandonados y mal criados. Los conflictos en los hogares y la falta de educación y ejemplo de los padres. Los accidentes y la violencia en las calles. A lo anterior se asocian: la acelerada urbanización y industrialización y el aumento de vehículos automotores causando hacinamiento, contaminación del ambiente y accidentes. Y por si fuera poco, se viene ahora a agregar la escasez de agua potable en la mayoría de los países incluyendo Costa Rica. Todo esto constituye "el ambiente social de la salud", y sobre el cual es posible influir en muchas formas. Por eso la educación para la salud y la prevención de las enfermedades y los accidentes nunca dejarán de tener vigencia.

\section{Tendencias de la Medicina en el Futuro}

Ya vimos que han sido innumerables los éxitos alcanzados a través de los siglos por la medicina para proteger la salud o curar la enfermedad. En los últimos 40 años los avances en el diagnóstico han sido muy grandes al disponerse de nuevas técnicas endoscópicas y arteriográficas para ver lesiones en diversas partes del cuerpo, además de la aparición de la radiología no invasiva como el ultrasonido, la tomografía y la resonancia magnética. En cirugía, los progresos en todos los campos han sido espectaculares en especial en la cardíaca, así como en los transplantes, la cirugía laparoscópica y la aparición de la cirugía robótica (a distancia) para los próximos años.

Uno de los grandes triunfos de la medicina se dio cuando por serendipia o un accidente feliz, Sir Alexander Fleming, en 1929, descubrió el hongo que producía la penicilina y que destruía numerosas bacterias gracias a lo cual se salvaron millones de vidas durante 30 años. Para algunos, su uso indiscriminado en personas y animales permitió la aparición de resistencias bacterianas. Para otros, sólo se han cumpli- 
do los postulados de la Teoría de la evolución que señala que la aparición de mutaciones en los genes desde la más remota antigüedad al presente, es un hecho natural y forma parte del proceso de adaptación para sobrevivir de todos los seres vivos en la naturaleza. La resistencia a los antibióticos de las bacterias son de dos tipos: la natural, grupos de bacterias nacen siendo resistente a determinados antibióticos, y la adquirida. Al principio sensibles las bacterias se vuelven resistentes por mutaciones espontáneas o por intercambio de fragmentos de ADN transferidos de un germen resistente a otro sensible.

Lo que preocupa, es que las mutaciones que dan resistencia a las bacterias y virus, están sucediendo más rápidamente que la capacidad que tiene el organismo y sus mecanismos inmunológicos defensivos para hacerles frente, o que la ciencia tiene para descubrir antídotos. De hecho en los últimos 30 años no se han producido nuevos antibióticos sino variantes de los mismos. No es sino hasta hace pocos meses que en Estados Unidos se están probando dos nuevos contra el estafilococo y el enterococo llamados linezolyl y daptomycin. Las resistencia de los estafilococos estreptocos y del bacilo de la tuberculosos son el mejor ejemplo de esto.

A mi juicio y en el futuro los antibióticos no ocuparán un lugar tan preferente para combatir las enfermedades infecciosas producidas por virus y bacterias.

Si ustedes recuerdan las mismas bacterias-virus-parásitos y hongos siguen provocando desde hace cientos de años las mismas infecciones en todo el mundo como son: las otitis medias, las encefalitis y meningitis, las amigdalitis, neumonias, bronquitis, gastroenteritis, el paludismo, el colera, el dengue, las vaginitis y muchas otras. Ahora con la desventaja de que se están haciendo resistentes a los antibióticos.

En el futuro, las curaciones se lograran gracias a vacunas contra el paludismo, sida y otras enfermedades infecciosas, algunos cánceres $\mathrm{y}$, posiblemente, hasta la enfermedad de Alzheimer se tratará así. Por otro lado, ya se está poniendo de moda la terapia genética, empleando genes sanos para sustituir a los mutados empleando virus buenos que los transportan como el onyx-015 en fase de experimentación. O el empleo de anticuerpos monoclonales: "misiles microscópicos" de proteínas especificas para sustituir las ausentes debida a lesión de los genes que las producen. Por transplantes de stem cell (células madres) para regenerar o formar tejidos sanos en diferentes órganos: piel en quemaduras, huesos en fracturas, hígado en cirrosis, glóbulos blancos en leucemias. En la lucha contra el cáncer se mejorarán los factores antioncogenos, que son drogas que inhiben el factorde crecimiento celular o vascular canceroso. Las terapias de quimio-prevención para evitar que se produzca el cáncer como es el caso del tamoxifen en los tumores de la mama. También se está ya experimentando con sustancias antimetástasis, enzimas capaces de bloquear las células malignas en la sangre o que disuelven los tejidos enfermos o cancerosos. Increíblemente se ha vuelto a utilizar el raticida "arsénico", veneno conoci- do empleado ahora a dosis bajas intravenoso en la leucemia mielocítica aguda para obtener remisiones de ésta y tiempo para poder conseguir un transplante de médula ósea. Además hay un nuevo producto para la leucemia mieloide crónica que destruye las células leucémicas y no toca las sanas llamado Gleevec al bloquear las proteínas anormales de crecimiento y reproducción celular producidas por genes lesionados. En fin, la gama de productos es múltiple e incluso se pueden emplear varios tratamientos combinados para mejorar su efecto. De esta forma desaparecerán algunas de las enfermedades y muchos cánceres.

No será ya matando las bacterias, que es lo que hacen los antibióticos que destruyen el 95\% de ellas, pero dejan las resistentes que luego pueden multiplicarse, sino aumentando los mecanismos naturales defensivos inmunológicos del organismo y mejorando los procesos de reparación celular y de genes dañados que se logren los nuevos avance en terapia. A eso se le conoce como "el ambiente biológico interior", muy importante y en muchos sentidos es el que mantiene la salud de las personas, aunque su acción es imposible de cuantificarla. El organismo de cada uno de los seres humanos reacciona ante la agresión de agentes externos debido al "sistema inmunológico adquirido" conformado por los glóbulos blancos y sus anticuerpos producidos en diferentes lugares del cuerpo. Estos están en constante guerra, defendiéndonos de las bacterias, virus, parásitos, tóxicos y carcinógenos, que ingresan a la circulación. Si por alguna causa este sistema se ve afectado por algún estrés psíquico o físico prolongado o por otras causas, al fallar podemos adquirir una enfermedad o el cáncer.

El "sistema inmunológico innato" poco estudiado al presente, está constituido por una serie de péptidos y pequeñas proteínas producidas por las mucosas de la boca, faringe, bronquios y aparato digestivo, capaces de atacar bacterias y parásitos lesionando sus membranas e impidiendo su ingreso a la sangre.

El otro mecanismo interno, está formado por "los mecanismos reparadores defensivos celulares", mediados por genes, sus enzimas y proteínas, y que constantemente reparan las lesiones del genoma o de las células. Si esto falla por mutación de esos genes reparadores puede aparecer una enfermedad o el cáncer. Esto se ha demostrado al comprobar que de miles de granjeros expuestos a pesticidas y yerbicidas, solo unos pocos desarrollan una leucemia por alteración de genes de los cromosomas 5 y 7 , cuyas mutaciones no pudieron ser reparadas como si sucedió con los restantes granjeros. Solamente el $15 \%$ de las personas que fuman en exceso y durante muchos años desarrollan cáncer en el pulmón. En los restantes sus mecanismos reparadores impiden el desarrollo del cáncer. Entre el 1\% al 5\% de los portadores de pólipos adenomatosos del colon llegan a desarrollar un cáncer, esto es debido a los mecanismos reparadores defensivos de los restantes.

Les recuerdo que Hipócrates decía: "las fuerzas naturales que se encuentran dentro de nosotros son las que verdaderamente curan las enfermedades". Posteriormente el galeno insistiría: 
"que el médico solo es el ayudante de la naturaleza".;Y seguimos igual!. Recuerden que la viruela es la única enfermedad que ha sido posible erradicar en el mundo, y el éxito se debe a una vacuna. Estamos a punto de eliminar la poliomielitis y es otra vacuna la causante del éxito. Gracias a la vacunación de los niños han descendido en todo el mundo, las muertes por tetanos, difteria, tosferina, sarampión, meningitis, tuberculosis y hepatitis. En estos casos lo que se hace es ayudarle al cuerpo a defenderse.

Viejas y Nuevas Enfermedades: Tanto en Costa Rica, como en el resto del mundo, aún no hemos podido vencer y han vuelto a tomar vigencia enfermedades como la tuberculosis, la malaria, el dengue y el cólera. Por otro lado, enfermedades que nunca se pensó que pudieran estar causadas por bacterias, están ahora siendo relacionadas con éstas. Este es el caso de las gastritis y las ulceras pépticas e incluso el linfoma MALT y el cáncer gástrico, en las cuales influye en su aparición una bacteria conocida como helicobacter pyloris. Se comienza a relacionar a la clamidia neumoniae a los citomegalovirus y a los enterococos con la aparición de arteroesclerosis y coronariopatías. A los herpes virus con algunos cánceres como los del cervix, nasofaringe y algunos linfomas e incluso a la chamidia neumoniae con la enfermedad de Alzheimer.

Ecología y Nuevas Enfermedades: Otro problema que creíamos tendríamos en el futuro, está ya presente, este consiste en la perdida del equilibrio en la naturaleza entre los seres y la aparición de nuevas enfermedades. Los seres humanos hemos olvidado que vivimos o cohabitamos el planeta tierra en unión de las plantas y los animales, incluyendo a las bacterias, virus, parásitos y hongos. Y que mantenemos en cierta forma un equilibrio o balance gracias al hábitat que cada uno tiene, al alterarlo se modifican las relaciones entre todos.

Por ejemplo, nosotros estamos colonizados por miles de millones de bacterias y posiblemente virus en nuestro aparato digestivo, que viven ahí sin hacernos daño y más bien contribuyen con su metabolismo, a la absorción de vitaminas y otras sustancias.

Los bacilos coli impiden cuando están en proporción normal, que otras bacterias como las salmonellas y los anaerobios proliferen en exceso en el intestino. Si tomamos antibióticos, destruimos las coli y pueden presentarse serias diarreas por proliferación de las otras bacterias o virus. Ahora existen una serie de mortales enfermedades que hasta hace pocos años no se conocían como las producidas por el virus del sida, el hantavirus, el Ebola, el de Hong Kong, el del Nilo y la "enfermedad de las vacas locas", una encefalitis del ganado vacuno que se trasmite supuestamente por la ingesta de carne contaminada y sus derivados, y que no es producida por un virus o bacteria, sino por un fragmento proteico llamado "prión". Éste produce una proteína extraña que lesiona el cerebro pudiendo afectar al ser humano. Como no conocemos como diagnosticarlo tempranamente y tampoco hay tratamiento, como única alternativa para evitarlo es convirtiéndonos en vegetarianos. Debemos señalar que ya desde hacía más de un siglo se conocía una encefalitis que afectaba a las ovejas llamada "El Scrapie", sin buena traducción al castellano y que hoy sabemos era provocada por un prión, pero en este caso no se trasmitía a las personas.

Lo anterior parece poner en evidencia que la activación de virus, bacterias y priones, que anteriormente estaban en la naturaleza afectando, como parásitos, a plantas, ratas, aves, monos y otros mamíferos incluso sin causarles lesiones, ahora provocan graves y mortales enfermedades en las personas.

Esto posiblemente se debe a la alteración del ambiente causado por el hombre con la deforestación de los bosques y selvas, la contaminación de los ríos y de la atmósfera y la aparición de grandes ciudades con hacinamiento y focos de suciedad y pobreza. Esto ocasiona la migración de parasitos, virus bacterias y priones de sus huéspedes naturales hacia nuevos huéspedes como mosquitos, ratas, gatos y perros de ciudades e incluso al ser humano. Otro problema está constituido por la facilidad del transporte aéreo para que personas enfermas se trasladen de un extremo a otro de la tierra e infecten a desprevenidas poblaciones enteras con cuadros gripales ahora, pero en el futuro podría ser una enfermedad más grave. En 1918 y 1919, una epidemia de influenza española se extendió por todos los países y mató 25 millones de personas en el mundo, en la actualidad, esto podría ser una cifra pequeña si aparece una epidemia de un tipo que no podamos controlar.

Además estamos viendo actualmente una "globalización de las enfermedades, el ejemplo de esto lo tenemos con: la enfermedad de las vacas locas, la encefalitis del virus del Nilo, la fiebre del valle del Rif que se ha visto en el Yemen y que en noviembre del 2000 mató a miles de vacas, ovejas y cabras y que se trasmitió a las personas. A eso se agrega el reciente brote al mismo tiempo en diferentes países de la "fiebre aftosa", que aunque no se trasmite al ser humano no deja de crear preocupación por estar diezmando al ganado. Por esa razón los médicos debemos colaborar con la conservación de la naturaleza y el ambiente.

\section{El Genoma Humano y la Medicina del Futuro}

Charles Darwin y Alfred Wallace son los padres de la teoría de la evolución por selección natural a la cual se le agrego posteriormente el conocimiento de la herencia genética de Mendel.

Gracias a esta teoría se llego a demostrar que las diversas especies de animales que pueblan la tierra incluyendo el hombre no eran inmutables y no habían sido creados de una sola vez en pocos días como afirmaba la Biblia sino que habían cambiado a través del tiempo. Hoy aceptamos que todo ser desciende de una especie preexistente y que las mutaciones las modifican. Existe una similitud tremenda entre todos los seres vivos ya sea vegetales, animales o el hombre, debido a que en el núcleo de sus células existe una molécula similar conocida como ADN o ácido desoxirribonucleico y que da 
lugar a los cromosomas. Tanto en las células vegetales como en las animales existen en el ADN los mismos componentes llamados bases (adenina, timina, guanina y citosina) que dan el llamado "código genético". La única diferencia es que esas bases no se encuentran en la misma proporción ni orden ya que varían en cada especie y en el tipo de gen que forman y a su vez en las proteínas que estos producen. La rata tiene 42 cromosomas, la mosca 8 , el maíz 20, el hombre 46 y la papa 48. Como se ve, tener muchos o pocos cromosomas no significa nada lo que importa es el tipo de gen que tienen.

La proteónica o estudio de las moléculas de proteínas, señala que existen entre 250 mil a un millón de proteínas humanas formadas a partir de los genes con ayuda de diferentes aminoácidos, algunos producidos en las células y otros llegan con los alimentos. Las proteínas están formadas por "átomos de: nitrógeno, hidrógeno, carbono y oxígeno. Esto muestra en la escala más inferior la similitud de todos los seres vivos formados por simples átomos que se organizan en moléculas y forman posteriormente células, tejidos, órganos y seres.

Las "mutaciones" en los genes de los diferentes seres primitivos fueron la causa para que se lograran especies superiores, y entre ellas el ser humano, pero a la vez la causa de sus enfermedades ya que diferentes sustancias o cancerígenos cuando afectan genes sanos trastornan su función y pueden dar lugar a anomalías, enfermedades y cáncer. Hay entre 30 a 40 mil genes en los 46 cromosomas que poseemos, estos tienen genes para: la respiración, el crecimiento y la división, la digestión y la reparación celular y de los propios genes. Por otro lado, otros genes y sus proteínas reprimen o frenan la división o el crecimiento e incluso parece haber "genes maestros" encargados de formar el embrión posterior a la fecundación. Ahora sabemos que los genes trabajan coordinadamente y muchas veces en conjunto para producir un tejido o una función como la cerebral.

Una célula sana se reproduce un máximo de 50 veces y luego fallece. Eso nos muestra que en los seres hay un mecanismo de muerte celular llamado "apoptosis" similar a la eutanasia. Pero que, si sus genes de división celular o los telómeros de los cromosomas de una célula están alterados y los genes inhibidores están inactivados por mutaciones, la célula puede reproducirse indefinidamente y hacerse inmortal ocasionando un cáncer.

Un simple cambio de un átomo en un gen por radicales libres del ambiente puede dar lugar a patología si la lesión no es reparada lo cual sucede miles de veces al día. En las enfermedades hereditarias se nace con lesión en un gen que si es un gen dominante se expresara en una enfermedad y si es recesivo requerirá del ambiente y de sustancias que lesionen el otro gen similar o alelo de su cromosoma antes de poderse expresar dando patología. Por supuesto las lesiones causadas por traumas y muertes violentas están fuera de la concepción genética-ambiental de las enfermedades, ya que aquí priva sólo el ambiente y el azar.
Desde hace años conocemos los beneficios que en el campo legal nos proporciona la llamada "prueba del ADN", que consiste en obtener una gota de sangre o semen y analizar ahí la disposición del ADN comparándolo con otra muestra en el que se quiere confirmar, por ejemplo, la paternidad de un hijo o la participación en un homicidio o una violación.

El proyecto del "genoma humano" iniciado hace varios años ha logrado identificar casi la totalidad de los 3.100 millones de bases o escalones del ADN. Ya se han logrado identificar varios miles de genes y tendrá que completarse esto para entonces identificar a su vez la o las proteínas que cada uno produce o contribuye a producir y cual es su función.

Lo anterior tendrá implicaciones no solo para las ciencias médicas, sino incluso para las ciencias sociales, como la ética, el campo legal e incluso la economía y la religión. El siguiente avance es poder entender las interacciones que existen entre el genoma humano y el ambiente en cuanto a la conducta de las personas y la violencia irracional de algunos individuos. Les recuerdo que los caracteres de las personas son heredados de padres a hijos a través de sus cromosomas.

Gracias a los estudios del genoma humano, es probable que en el presente siglo asistamos a un escenario de la salud que podría creerse producto de la ciencia ficción.

Este podría ser tan simple y tan fantástico como lo siguiente:

1- Al nacer un niño, en el hospital se le toma una muestra de sangre o una biopsia de piel. 2- Esta es enviada a un "banco de datos del genoma humano" ya sea del estado, del seguro social o privado. 3- Ahí se analizan los genes de la muestra enviada y se comparan con el genoma "estándar" del ser humano ya para esa época completado no sólo en la cantidad y características de sus genes sino con las proteínas y la función que cada una tiene. 4- Las alteraciones que se aprecien si ya vienen mutados pueden dar lugar a que se reporte a la familia de acuerdo con lo encontrado lo siguiente: qué enfermedades hereditarias va a padecer (una o varias) o qué predisposición tiene a sufrir algunas enfermedades bajo la acción de mutantes del ambiente sobre sus genes durante su vida. Gracias a eso la medicina podría llegar entonces a ser más preventiva que curativa. 5- Lo anterior tendrá tremendas implicaciones no solo para el niño, sino también para los padres, los servicios médicos y de salud y los seguros de vida, en el aspecto de los derechos humanos, sobre la "confidencialidad de la salud y la enfermedad de las personas". 6- el problema es que aparte de lo anterior, creará graves angustias a los padres, al conocer las próximas o lejanas enfermedades que padecerán sus hijos, sobre todo si no hay cura para ellas o no tienen medios económicos para tratarlas.

7-Por otro lado, que pasaría si alguna ley permite que los las empresas conozcan o puedan exigir el curriculum genético de sus empleados. Posiblemente sólo se emplearán a los pocos con un futuro sano. O si al solicitar un seguro de vida o de atención de enfermedad se nos exige que nos hagamos un mapeo genético. 8- Que pasa si el niño ya de joven o adulto 
exige conocer su futuro genético y sus posibilidad de enfermar. No podríamos crear una civilización de hipocondríacos, donde los individuos viven con el temor a la enfermedad que los afectara en el futuro. Y no temo equivocarme al pensar que muchos padres (suegros) le exigirán al novio o a la novia, aparte de tener un buen trabajo o profesión, aportar su curriculum genético para ver los riesgos hereditarios de sus futuros nietos.

No podría dar lugar el conocimiento del genoma humano a una división entre personas normales (que no serán muchos seguramente), los anormales (porque sufrirán o tiene predisposición a tener alguna enfermedad), estigmatizando así al ser humano desde su nacimiento. Acabamos de ver como los avances científicos de la fertilización in vitro en los Estados Unidos dieron lugar al nacimiento de un bebe seleccionado genéticamente de no sufrir la anemia de Falconi para que pudiera aportar células madres" a su hermanita que la padecía y estaba condenada a morir si no se recibía un transplante de estas. Ahora se está recuperando empleando "stem cells" obtenidas de la sangre del cordón umbilical. Este es un logro impresionante de la medicina moderna y nos muestra que ya se está en capacidad de seleccionar niños con características definidas según necesidad de las familias o de la ciencia. Pero, ¿la medicina y la ciencia sólo actuarán en estos casos con fines tan altruistas? ¿no podría en el futuro hacerse lo mismo para obtener una raza superior ? ¿será conveniente?

Me temo, que en poco tiempo comenzaremos a jugar a ser dioses, ya que estaremos aduiriendo la capacidad de predecir el futuro de una persona, para bien o para mal.

Exitos como estos que llegan a tocar puntos neurálgicos de la moral y la religión, crean en algunos sectores sociales desconfianza en los avances tan acelerados de la ciencia y la medicina. Lo anterior, unido a la imperfección del ser humano que puede abusar de los descubrimientos para beneficio de unos pocos y no de la humanidad, obligará a reglamentar la aplicación de estos conocimientos para evitar problemas con ellos.

Para finalizar hay tres aspectos trascendentales en el campo de los cuidados de la salud del ser humano a los que me voy a referir. El primero, y que parece un contrasentido, es la existencia del llamado "paradigma virtual de los cuidados de la salud". Este consiste en que no está demostrado que lograr una buena salud en la población reduce las demandas de servicios médicos y por consiguiente sus costos, en especial los hospitalarios. La paradoja es que, al mejorarse la salud, disminuye la mortalidad y aumenta la esperanza de vida con el consiguiente envejecimiento de la población. Aparecen entonces en ella las enfermedades crónicas de la tercera edad ya citadas. Todas ellas de difícil y costosa atención y sin garantía de buenos resultados a largo plazo.

La segunda es que debemos insistir en que las campañas educativas y los cuidados de la salud deben ser encaminados no sólo a lograr darle a la población una mayor esperanza de vida, sino sobre todo a proporcionar una mejor calidad de vida a las personas.

El tercero y último punto, es que no nos llamemos a engaño, al presente y todavía por muchos años, el paradigma o modelo que prevalece es el "paradigma de atención de la enfermedad". Los cuidados de la salud son aún cuidados de la enfermedad, en su mayoría, y hacia ellos va destinado más del 80 por ciento del presupuesto de salud en casi todos los países. La razón fundamental es que las personas piden en cualquier comunidad o país que lo primero que debe garantizarse es la atención de sus enfermos. Lo segundo, es que la gente cree que si llega a enfermar la ciencia médica con sus espectaculares avances reparará sus daños. Pero esto no es posible en muchos casos.

Por esa razón existe lamentablemente el "paradigma perdido de la prevención" debido a que a la gente no le gusta evitar factores de riesgo; abusa del comer y beber, de la relación sexual promiscua, del fumado y las drogas, de la velocidad y se expone a múltiples riesgos en su trabajo, los deportes o en su ambiente y no mantiene buenas relaciones humanas en su hogar y trabajo.

Los medios de comunicación visual estimulan a los jóvenes al consumo de bebidas, al fumado y al sexo. La violencia y el empleo de las armas son expuestos como formas naturales para resolver problemas personales o conflictos. Se hace apología y se admira a los artistas violentos de la televisión y el cine y los niños y jóvenes los imitan. Todo esto dificulta la educación para la salud y la prevención.

En una oportunidad le preguntaron a Niccolo Maquiavelo el analista político florentino del renacimiento (1500 años d.C) que consejo daría a los príncipes de los estados italianos que permanecían en constantes guerras entre ellos e impedían la unificación de Italia. Para esto dijo, hay que estudiar las causas que las provocan y evitarlas. Y puso el siguiente ejemplo.

"Los médicos dicen de la tisis (tuberculosis), es al principio fácil de curar y difícil de conocer, mientras que con el correr del tiempo, no habiendo sido al principio conocida ni remediada, ya es fácil de conocer pero muy difícil de curar.

Lo anterior puede ser perfectamente aplicado a las enfermedades y algunos cánceres. Debemos tratar por todos los medios posibles que éstas no se presenten, evitando los factores de riesgo que las condicionan.

Esta claro ya la grave alteración del ambiente, a lo que se agregan los continuos enfrentamientos entre personas y pueblos no sólo por aspectos políticos o ideológicos, sino en mucho por la irreflexión y decidia del hombre. Esto es debido a que, la conducta humana no esta gobernada únicamente por las necesidades biológicas como en los animales, que matan sólo para comer o defenderse, sino también por el egoísmo, las pasiones, la agresividad, la falta de educación y el deseo de dinero y poder. 
La vida, dice el famoso médico y científico Rene Duboz, es una aventura que se desarrolla en un mundo en que nada es estático, y en el que aparecen sucesos impredecibles y apenas comprendidos y que a veces representan peligros que deben superarse. Lamentablemente el hombre a semejanza del aprendiz de brujo, ha desatado fuerzas potencialmente destructivas que pueden algún día escapar de sus dominios.

De la mente del ser humano y especialmente de su educación y su ética, así como de su formación espiritual depende que eso no suceda. Pero como ya hemos señalado, la ausencia de luchas y enfermedades es incompatible con la vida en la naturaleza, por eso, la eliminación de la enfermedad en forma total y duradera, es únicamente un sueño como lo es también pretender alcanzar el paraíso

\section{Lecturas recomendadas}

1. American Public Health Association. Changes in mortality rates are based on age-adjusted data. In. Lifestyle Blues. Scientific American. 284 (4), 18, April 2001.

2. Aurelio Cornelio Celso. Los ocho libros de la Medicina. Ed. Iberia, S.A. Barcelona,Tomos I y II, 1966.

3. Day NP, Moore CE, Enright MC, Berendt AR, Smith JM, Murphy MF, Peacock SJ. A link between virulence and ecological abundance in natural populations of Staphylococcus aureus. Science 2001; 292 (5512): 114-116.

4. Davies J. In a map for human life, count the microbes, too. Science 2001; 291 (5512): 2316.

5. Dubos René. Un Dios Interior. Salvat Editores, S.A. Barcelona, 1986. E.A.U. Hippocrates. Encyclopaedia Britannica. Macropaedia. Enciclopaedia Britanica Inc.Chicago 1977; 8: 942-943.

6. Encarta Ecyclopedia. Hippocrates. Encarta 98 Encyclopedia. Microsoft Multimedia.United States, 1998.

7. Garrison H. Historia de la Medicina. Medicina Griega. Ed. Interamericana, S.A. Cuarta edición. México 1966; Capítulo IV, 49-96.

8. Grolier Encyclopedia. Hippocrates.Grolier Multimedia Encyclopedia Grolier Inc. United States of America, 1998.

9. Gura T. Innate Immunity. Ancient System gets new respect. Science 2001; 291 (5511): 2068-71.

10. Jaramillo Antillón J. El Cáncer. Historia. Editorial Universidad de Costa Rica, Tomo I,27-29,1991. Salud y Seguridad Social. Editorial Universidad de Costa Rica.

11. Jaramillo Antillón J. Changes in health care strategies in Costa Rica. Bull Pan Am Health Organ 1987; 21 (2): 136-148.

12. Jaramillo Antillón J. Strategy, changes in health care in Costa Rica., Tokyo: Integration. JOICFO, 1988: 17, 2-17.

13. Jaramillo Antillón J, Mora Morales E. Enfermedades del tiroides y paratiroides. Historia. Editorial Universidad de Costa Rica 1978; 13-21.

14. Jaramillo Antillón J, Arrea Baixench C. Status of health and the medical service in Costa Rica. 7th Annual Conference. International Health Medical Education Consortium. March 4-8,1998.
15. Jauhar. Sandiep. Finding cancer drugs in the most unliked places. Health \& Fitnes. The New York Times. New York, 7/D, April 10, 2001

16. Jones WHS. Hippocrates and the Corpus Hippocraticum. London Press, London, 1945

17. Laín Entralgo P. Historia de la Medicina. El saber médico en la Antigüedad Clásica. Salvat Editores, S.A. Barcelona 1982: Sección II, $59-110$

18. L Elaut. El Testamento de Hipócrates. Organorama, Madrid, año 12. No.3, 18-22, 1975 .

19. Lipsitch M. Microbiology. Bacterial population genetics and disease. Science 2001; 292 (5514): 59-60.

20. Litre E. Oeuvres complètes d'Hippocrate. 10 vol, Ed. Masson. Paris, 1961

21. Lloyd CER. Hipocratic Writing. Penguin Book. Hammondsworth, London, 1978.

22. Machiavelli N. El Príncipe- Escritos Políticos. 6ta.ed, Ediciones Aguilar, S.A. Madrid 1966

23. National Comission on Comunity Health Service. Health is a community Affair. Harvard University Press. Cambridge, 1966.

24. Nicolaou KC, Boddy CN. Behind Enemy Lines. Sci Am 2001; 284 (5): 54-61.

25. Pérez Tamayo R. La Fábrica de Andrés Vesalio. En la Profesión de Burke y Hare, Fondo de Cultura Económica. México 1996; 13-42.

26. Pérez Tamayo R. Las Momias, El Unicornio y Ambrosie Paré. En la Profesión de Burke y Hare, Fondo de Cultura Económica. México 1996; 53-82.

27. Pineault R. The place of prevention in the Quebec health care system. Can J Public Health 1984; 75: 92-97.

28. Raventós H. Elucubraciones acerca del proyecto del Genoma Humano y la Práctica Clínica. Gaceta Médica de Costa Rica 2000; 2 (3): 5-7.

29. Reale G, Antiseri D. Historia del pensamiento filosófico y científico antiguo. Hipócrates y el Corpus Hippocraticum. Ed. Herder, Barcelona 1988; Tomo I, Cap V: 107-115.

30. Singer Ch, Underwood E A. Breve Historia de la Medicina. Ediciones Guadarrama. Madrid 1966

31. Terris M. La revolución epidemiológica y la medicina social. Editorial Siglo XXI. México 1980

32. The Editors. Save Embryonic Stem Cell Research. Sci Am 2001; 284 (5): 4.

33. White F. Epidemiology in Health Promotion: a Canadian perspective. Bull Pan Am Health Organ 1989; 23 (4): 384-395.

34. World Health Organization. Targets for Health for all. Pub.WHO: Copenhagen, 1986

35. World Health Organization. Health Objectives in Public Policy. Harvard Institute for International Development: Cambridge,July, 1987.

36. Yam P. Mad cow's human toll. Sci Am 2001; 284 (5): 10-11. 